\title{
Survival, fusion, and hardware failure after surgery for spinal metastatic disease
}

\author{
Timothy J. Yee, MD, ${ }^{1}$ Yamaan S. Saadeh, MD, ${ }^{1}$ Michael J. Strong, MD, PhD, ${ }^{1}$ Ayobami L. Ward, MD, ${ }^{1}$ \\ Clay M. Elswick, MD, ${ }^{2}$ Sudharsan Srinivasan, MS, ${ }^{1}$ Paul Park, MD, ${ }^{1}$ Mark E. Oppenlander, MD, ${ }^{1}$ \\ Daniel E. Spratt, MD, ${ }^{3}$ William C. Jackson, MD, ${ }^{3}$ and Nicholas J. Szerlip, MD ${ }^{1}$
}

\begin{abstract}
Departments of ${ }^{1}$ Neurosurgery and ${ }^{3}$ Radiation Oncology, University of Michigan, Ann Arbor, Michigan; and ${ }^{2}$ Brain and Spine Specialists of North Texas, Arlington, Texas
\end{abstract}

\begin{abstract}
OBJECTIVE Decompression with instrumented fusion is commonly employed for spinal metastatic disease. Arthrodesis is typically sought despite limited knowledge of fusion outcomes, high procedural morbidity, and poor prognosis. This study aimed to describe survival, fusion, and hardware failure after decompression and fusion for spinal metastatic disease.

METHODS The authors retrospectively examined a prospectively collected, single-institution database of adult patients undergoing decompression and instrumented fusion for spinal metastases. Patients were followed clinically until death or loss to follow-up. Fusion was assessed using CT when performed for oncological surveillance at 6-month intervals through 24 months postoperatively. Estimated cumulative incidences for fusion and hardware failure accounted for the competing risk of death. Potential risk factors were analyzed with univariate Fine and Gray proportional subdistribution hazard models.
\end{abstract}

RESULTS One hundred sixty-four patients were identified. The mean age \pm SD was $62.2 \pm 10.8$ years, $61.6 \%$ of patients were male, $98.8 \%$ received allograft and/or autograft, and $89.6 \%$ received postoperative radiotherapy. The KaplanMeier estimate of median survival was 11.0 months (IQR 3.5-37.8 months). The estimated cumulative incidences of any fusion and of complete fusion were $28.8 \%(95 \% \mathrm{Cl} 21.3 \%-36.7 \%)$ and $8.2 \%(95 \% \mathrm{Cl} 4.1 \%-13.9 \%)$. Of patients surviving 6 and 12 months, complete fusion was observed in $12.5 \%$ and $16.1 \%$, respectively. The estimated cumulative incidence of hardware failure was $4.2 \%(95 \% \mathrm{Cl} 1.5-9.3 \%)$. Increasing age predicted hardware failure (HR 1.2, $p=0.003)$.

CONCLUSIONS Low rates of complete fusion and hardware failure were observed due to the high competing risk of death. Further prospective, case-control studies incorporating nonfusion instrumentation techniques may be warranted. https://thejns.org/doi/abs/10.3171/2020.8.SPINE201166

KEYWORDS spinal metastasis; surgical oncology; survival; fusion; hardware failure; reoperation

$\mathrm{T}$ HE spine is the most common site of osseous metastatic disease, ${ }^{1}$ and spinal metastases result in substantial pain, disability, and healthcare costs., ${ }^{2,3}$ While the benefits of circumferential spinal cord decompression with adjuvant radiotherapy have been well established, ${ }^{2,4-6}$ those of bony fusion in this population are incompletely understood. In nononcological populations, attainment of solid fusion is associated with superior functional outcomes and lower reoperation rates compared with pseudarthrosis. ${ }^{7-10}$ Especially in the absence of fusion, cyclical physiological loads weaken metal constructs and increase the risk of fatigue failure. ${ }^{11,12}$ However, fusion may be challenging to achieve in those with spinal me- tastases secondary to poor nutritional status, radiotherapy, and chemotherapy. ${ }^{13-17}$ Furthermore, as large retrospective studies continue to demonstrate a median survival of less than 1 year, ${ }^{18-21}$ there may be insufficient time for fusion to occur. ${ }^{14}$

One may also question whether fusion is necessary for a good outcome in the metastatic population of patients with metastases. The few radiographic fusion studies of these patients are small, lack criteria for fusion assessment, and vary widely in their fusion estimates, ranging from $17.6 \%$ to $100 \% .22-27$ While traumatic thoracolumbar burst fractures have been successfully managed with percutaneous fixation without fusion, the studies often ex- 
clude patients with neurological deficits requiring direct decompression. ${ }^{28-31}$ In contrast, the circumferential decompression employed in oncological patients is almost invariably destabilizing. While traumatic and oncological populations also have divergent potentials for survival and fusion, emerging studies are assessing nonfusion techniques in patients with spinal metastases. A common primary endpoint has been the hardware failure rate, which has ranged from $2.1 \%$ to $8.6 \% .{ }^{32-34}$ This appears to overlap with the reported rates of hardware failure when fusion is performed, ranging from $1.9 \%$ to $12.5 \% .^{3,35-38}$ These recent studies, however, have not incorporated both survival and fusion data in their interpretation of hardware failure.

In this study, we sought to comprehensively describe the outcomes of patients with spinal metastatic disease. We report time-dependent and risk-adjusted data on survival, radiographic fusion, and hardware failure. Based on extant studies and institutional experience, we hypothesized that both fusion rates and hardware failure rates would be low due to short postoperative survival.

\section{Methods}

This study was approved by the University of Michigan IRB. Patient consent was unnecessary, as all medical records were in existence at the time of IRB application submission and as the data set was devoid of identifiable patient information.

\section{Study Design and Patient Population}

We performed a single-center retrospective cohort study of patients 18 years of age or older who underwent decompression and instrumented fusion for spinal metastatic disease between July 1999 and November 2018. Anterior, lateral, and posterior approaches were included. Surgical indications included symptomatic spinal cord compression, radiculopathy, and spinal instability. For survival outcomes, patients were followed until the date of death or loss to follow-up. When available, CT scanning was utilized to assess fusion at $6,12,18$, and 24 months postoperatively, barring death or loss to follow-up. These CT scans were originally obtained for oncological surveillance. Partial fusion was defined as bony growth across the intervertebral space and/or facet joints of at least one, but not all, instrumented segments. We utilized the term "partial fusion" instead of "pseudarthrosis" due to the unknown timeline of fusion in the oncological population and the possibility of progressing to complete fusion. Complete fusion was defined as bony growth across the intervertebral space and/or facet joints of all instrumented segments. Unilateral fusion across all instrumented segments was considered complete. Multiple raters performed the assessments, and a single blinded rater (T.J.Y.) independently scored the CT scans to ensure accuracy. Hardware failure included any instrumentation aberrancy (e.g., rod breakage, screw breakage, screw pullout, cage subsidence) requiring reoperation.

\section{Statistical Analysis}

Descriptive data were analyzed with univariate instruments. Continuous variables were described with the
TABLE 1. Demographics of the cohort $(n=164)$

\begin{tabular}{cc}
\hline & Value \\
\hline Age, yrs, mean \pm SD & $62.2 \pm 10.8$ \\
\hline Male sex, $\mathrm{n}(\%)$ & $101(61.6)$ \\
\hline Tumor origin, $\mathrm{n}(\%)$ & \\
\hline Renal & $43(26.2)$ \\
\hline Lung & $25(15.2)$ \\
\hline Sarcoma & $19(11.6)$ \\
\hline Breast & $17(10.4)$ \\
\hline Prostate & $14(8.5)$ \\
\hline Hematologic & $9(5.5)$ \\
\hline Unknown/other & $7(4.3)$ \\
\hline Oropharyngeal & $7(4.3)$ \\
\hline Skin & $7(4.3)$ \\
\hline Thyroid & $5(3.1)$ \\
\hline Hepatic & $3(1.8)$ \\
\hline Bladder & $3(1.8)$ \\
\hline Colorectal & $3(1.8)$ \\
\hline Pancreatobiliary & $2(1.2)$ \\
\hline
\end{tabular}

mean and categorical variables with frequency. Survival was described with the Kaplan-Meier curve. Time to fusion was described with cumulative incidence functions accounting for the competing risk of death from any cause. Given the low hardware failure rate, analyses of potential risk factors were performed with univariate instead of multivariate Fine and Gray proportional subdistribution hazard models. Potential risk factors included age, sex, instrumentation across a junctional level, and number of levels instrumented. These analyses were not adjusted for multiple comparisons and were therefore considered exploratory; $\mathrm{p}<0.05$ was considered significant.

\section{Results}

We identified 164 patients who underwent decompression and instrumented fusion for spinal metastatic disease between 1999 and 2018. The mean age \pm SD was 62.2 \pm 10.8 years, and $61.6 \%$ of patients were male. The most common primary malignancies were renal (26.2\%), lung (15.2\%), sarcoma (11.6\%), and breast (10.4\%) (Table 1). The median number of levels of instrumented fusion was 4 (IQR 3.5-6), and the most common region instrumented was the thoracic spine (47.6\%). Cement-augmented screws were used in $3.7 \%$ of patients. Allograft and/or autograft was employed in $98.8 \%$ of patients, and allograft was exclusively employed in $90.9 \%$ of patients. Autograft from uninvolved iliac crest or spinous processes was not used after 2014. Postoperative radiotherapy was administered in $89.6 \%$ patients: stereotactic body radiotherapy in $59.2 \%$ and conventional radiotherapy in the remaining patients (Table 2).

The Kaplan-Meier estimate of median survival was 11.0 months (IQR 3.6-37.8 months) (Fig. 1). Among the 164 patients in the cohort, $50.6 \%$ had imaging data available for fusion assessment. Of the 86 patients surviving 
$\geq 6$ months, $82.3 \%$ underwent 6-month CT scanning; of the 60 patients surviving $\geq 12$ months, $63.3 \%$ underwent 12 -month CT scanning; of the 45 surviving $\geq 18$ months, $66.7 \%$ underwent 18-month CT scanning; and of the 32 surviving $\geq 24$ months, $81.3 \%$ underwent 24-month CT scanning. Among the 81 patients in the entire cohort without imaging data, $82.3 \%$ survived $<6$ months.

At the last radiographic follow-up, the simple proportions of patients attaining any fusion (partial or complete) and complete fusion were $23.2 \%$ and $6.1 \%$, respectively. Among the 33 patients observed to have partial fusion at any point, $5(15.2 \%)$ progressed to complete fusion. Utilizing a cumulative incidence function accounting for the competing risk of death, the estimated incidences of any fusion and complete fusion were $28.8 \%$ (95\% CI $21.3 \%-$ $36.7 \%$ ) (Fig. 2) and 8.2\% (95\% CI 4.1\%-13.9\%) (Fig. 3), respectively. Among patients surviving at least 6 months (43.9\% of the cohort), 12 months (34.1\% of the cohort), 18 months (25.6\% of the cohort), and 24 months (18.3\% of the cohort), the simple proportions with complete fusion were $12.5 \%, 16.1 \%, 19.1 \%$, and $20.0 \%$, respectively.

The risk of hardware failure requiring reoperation was $3.1 \%$. The earliest time to hardware failure was 1.1 months, and the longest was 44.3 months. The risk-of-death-adjusted estimated cumulative incidence was $4.2 \%(95 \%$ CI 1.5\%-9.3\%) (Fig. 4). All 5 patients who experienced hardware failure received allograft, and 1 received both allograft and autograft (Table 3). Four of these patients underwent postoperative stereotactic body radiotherapy, and 1 had conventional radiotherapy. None achieved complete fusion. Two achieved partial fusion by their 12-month follow-up CT studies, both prior to reoperation for hardware failure at 15.4 and 18.4 months. Using univariate Fine and Gray proportional subdistribution hazard models, increasing age independently predicted hardware failure (HR 1.2, $\mathrm{p}=0.003$ ). Sex, instrumentation across a junctional level, and number of levels instrumented were not associated with hardware failure. Sixteen patients $(9.8 \%)$ were found to have screw haloing that did not require reoperation.

\section{Discussion}

While the benefits of fusion have been well established for degenerative conditions, its necessity and feasibility in spinal metastatic disease are less clear. A primary concern is that this population may have insufficient survival for fusion to occur. While improvements in systemic therapies have lengthened survival in patients with select histologies such as non-small cell lung cancer and renal cell carcinoma, ${ }^{39}$ large studies continue to demonstrate an aggregate median survival of 12 months or less. ${ }^{18-21}$ Our median survival estimate of 11.0 months is consistent with this literature.

Another concern is that fusion may be impaired by poor nutritional status, radiotherapy, and chemotherapy. ${ }^{13}$ Unfortunately, the timing and process of fusion are incompletely understood. Extant radiographic studies including only metastatic disease are small, vary widely in fusion rates, and disproportionately focus on cervical metastatic disease. Heidecke and colleagues reported a $96.8 \%$ fusion rate in 62 patients undergoing anterior cervical decom-
TABLE 2. Treatment characteristics of the cohort $(n=164)$

\begin{tabular}{cc}
\hline \multicolumn{1}{c}{ No. of Patients (\%) } \\
\hline No. of levels instrumented & $142(86.6)$ \\
\hline$\leq 6$ & $22(13.4)$ \\
\hline$>6$ & $4(2.4)$ \\
\hline Instrumented region & $15(9.2)$ \\
\hline Occipitocervical & $29(17.7)$ \\
\hline Cervical & $78(47.6)$ \\
\hline Cervicothoracic & $23(14)$ \\
\hline Thoracic & $11(6.7)$ \\
\hline Thoracolumbar & $3(1.8)$ \\
\hline Lumbar & $1(0.6)$ \\
\hline Lumbosacral & $5(3.1)$ \\
\hline Sacroiliac & $149(90.9)$ \\
\hline Graft type & $8(4.9)$ \\
\hline Autograft only & $2(1.2)$ \\
\hline Allograft only & \\
\hline Both & $60(36.6)$ \\
\hline None & $87(53)$ \\
\hline Postop radiation & $17(10.4)$ \\
\hline Conventional & \\
\hline SBRT & \\
\hline None & \\
\hline
\end{tabular}

SBRT = stereotactic body radiotherapy.

pression and fusion, ${ }^{25}$ Oda and colleagues found a $40 \%$ fusion rate in 5 patients undergoing posterior cervical decompression and fusion, ${ }^{26}$ Chuang and colleagues reported a $100 \%$ fusion rate in 9 patients undergoing anterior cervical decompression and fusion, ${ }^{24}$ and Omeis and colleagues reported a $100 \%$ fusion rate in 4 patients undergoing anterior decompression and circumferential fusion. ${ }^{27}$

Fang and colleagues studied 41 patients with solitary thoracolumbar metastases who underwent spondylectomy with posterior instrumented fusion or anterior corpectomy with polymethylmethacrylate or autograft reconstruction. ${ }^{22}$ They found a $17.6 \%$ fusion rate for the small spondylectomy group $(\mathrm{n}=17)$ but did not report fusion rates for the anterior corpectomy group. They did not state when radiographic follow-up was performed or how fusion was assessed. As they only included patients with solitary vertebral metastasis, their findings may not be generalizable to patients with a higher burden of disease. Despite their 1-year survival rate of greater than $75 \%$, they reported no hardware failure events. This could be related to the bony health of patients with low metastatic burden or to their reported lack of routinely administered radiotherapy. Harel and colleagues retrospectively studied 15 patients who underwent decompression and instrumented fusion with at least 6 months of follow-up. ${ }^{23}$ They reported a fusion rate of $30 \%$ and a symptomatic hardware failure rate of $20 \%$, though they did not specify whether reoperation was performed. Neither was associated with radiation modality, but the study was likely underpowered. They did not describe when or how fusion was assessed. Furthermore, 


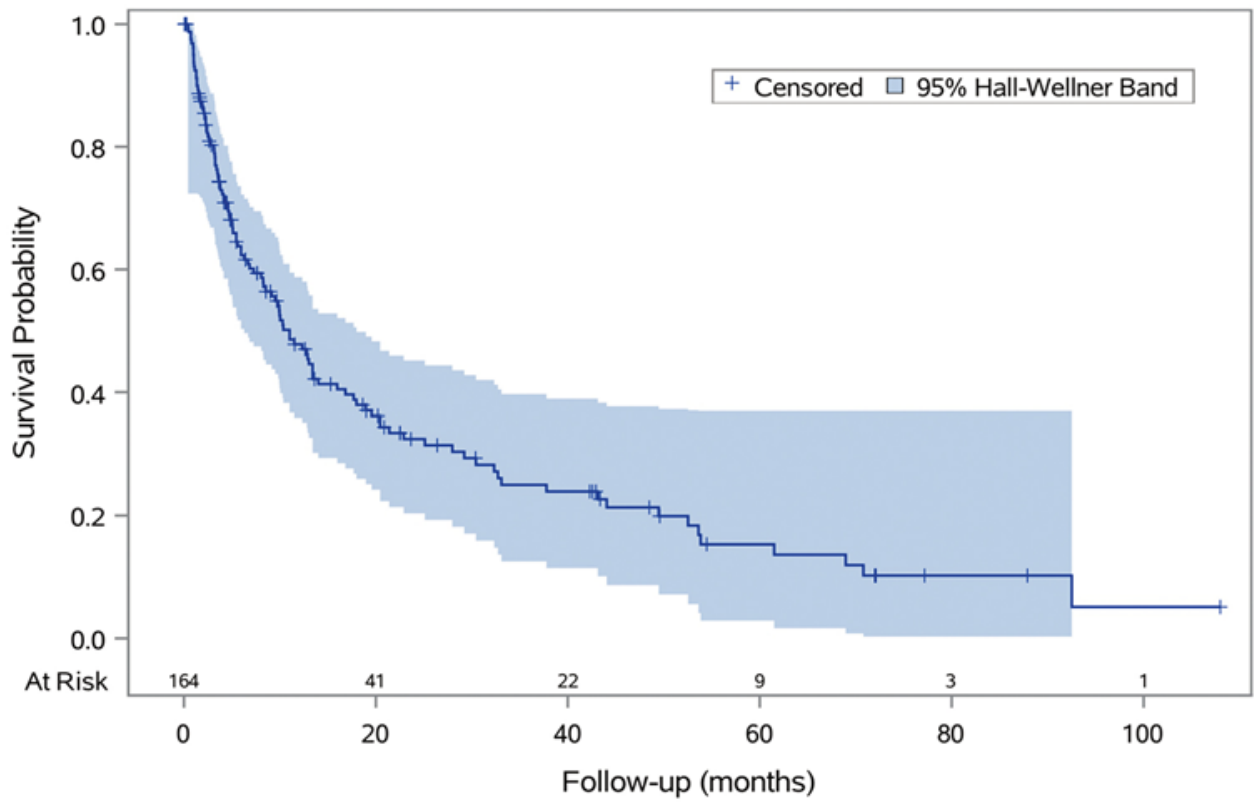

FIG. 1. Kaplan-Meier survival curve for the overall cohort. Figure is available in color online only.

excluding patients surviving less than 6 months will artificially increase observed fusion rates.

We report substantially lower rates of fusion, with a cumulative incidence estimate of $8.2 \%$ for complete fusion. The advantages of our study include its large sample size, consistently applied fusion criteria, serial assessment by CT scanning, and incorporation of competing risk analysis. Time-dependent and risk-adjusted analyses are essential for studying the metastatic disease population, given their short survival. While we also estimate a cumulative incidence of $28.8 \%$ for any fusion, the clinical benefit of having as little as one segment fused in a multilevel construct remains unclear, except for the mere knowledge that fusion is occurring.

If fusion rates are as low as our data suggest, hardware failure rates may be a more clinically useful metric following decompression and instrumentation. Existing studies of hardware failure rates unfortunately lack radiographic

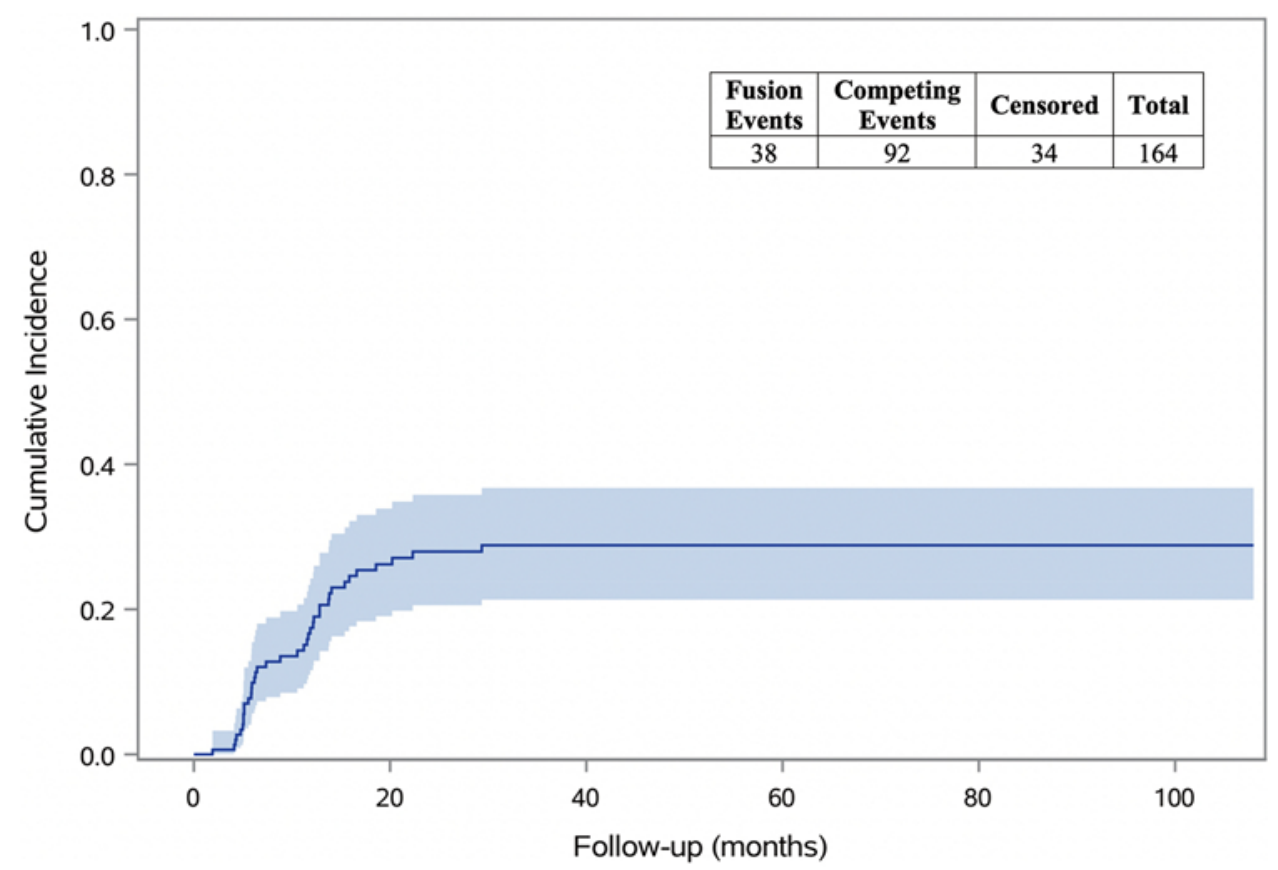

FIG. 2. Cumulative incidence function of achieving partial or complete fusion accounting for the competing risk of death. Shaded area represents the $95 \%$ confidence interval. Figure is available in color online only. 


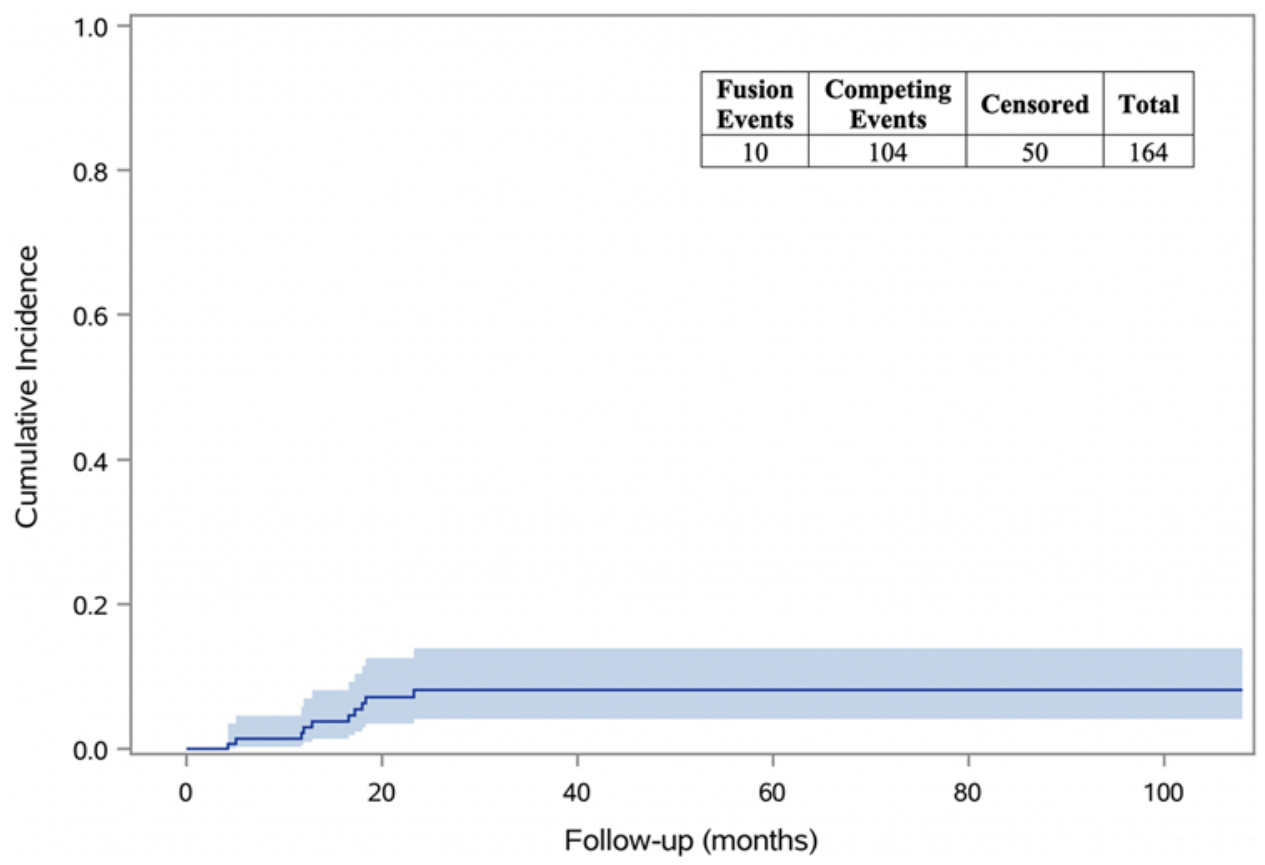

FIG. 3. Cumulative incidence function of achieving complete fusion accounting for the competing risk of death. Shaded area represents the $95 \%$ confidence interval. Figure is available in color online only.

fusion outcomes for comparison. Dea and colleagues reported a $2.0 \%$ risk of early construct failure in 101 patients undergoing emergency surgery for spinal metastasis; however, 6 patients underwent decompression only, the "early" time period was not defined, and the calculation was not risk adjusted for death. ${ }^{40}$ This is relevant given their high in-hospital mortality of $10.9 \%$ and the short median surviv- al of 8.4 months. Quraishi and colleagues reported a 3.1\% rate of instrumentation failure requiring revision among 289 patients, although the proportion who underwent instrumented fusion is unclear, their rate was unadjusted, and 95 patients were excluded due to insufficient information, potentially introducing large selection bias. ${ }^{41}$ Pedreira and colleagues reported a $1.9 \%$ risk of hardware failure requir-

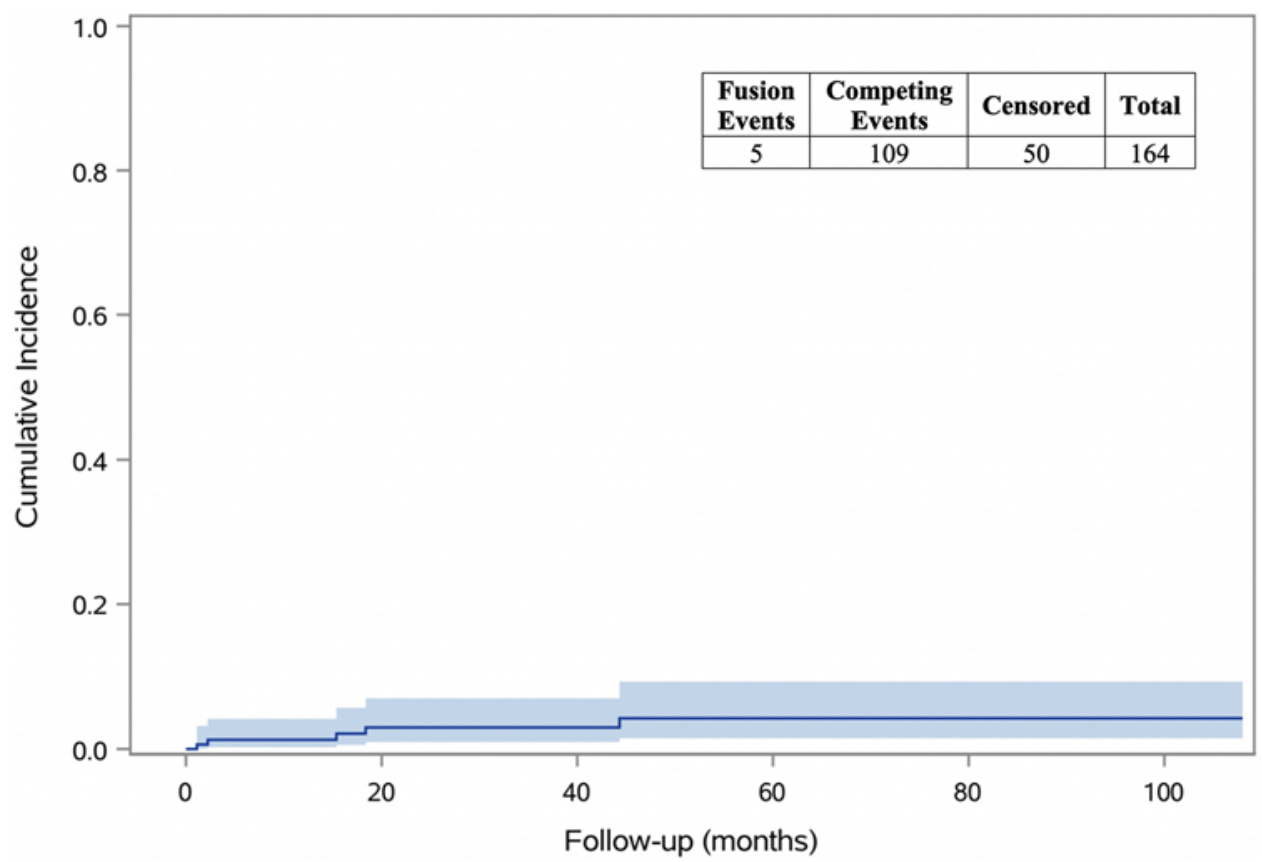

FIG. 4. Cumulative incidence function of hardware failure accounting for the competing risk of death. Shaded area represents the $95 \%$ confidence interval. Figure is available in color online only. 
TABLE 3. Characteristics and interventions for the 5 patients who experienced hardware failure

\begin{tabular}{|c|c|c|c|c|c|c|c|c|}
\hline $\begin{array}{l}\text { Age } \\
(y r s) \\
\text { Sex }\end{array}$ & $\begin{array}{l}\text { Tumor } \\
\text { Origin }\end{array}$ & $\begin{array}{c}\text { Index } \\
\text { Decompression }\end{array}$ & $\begin{array}{c}\text { Index } \\
\text { Arthrodesis }\end{array}$ & $\begin{array}{l}\text { Graft } \\
\text { Type }\end{array}$ & $\begin{array}{l}\text { Radiation } \\
\text { Type }\end{array}$ & $\begin{array}{l}\text { Time to } \\
\text { Failure } \\
\text { (mos) }\end{array}$ & $\begin{array}{c}\text { Failure } \\
\text { Description }\end{array}$ & Intervention \\
\hline $65.8, \mathrm{~F}$ & Breast & T2 & C6-T4 & $\begin{array}{l}\text { Allograft \& } \\
\text { autograft }\end{array}$ & Conventional & 1.1 & Bilateral rod breakage & $\begin{array}{l}\text { Extension of instrumentation \& fu- } \\
\text { sion w/ allograft to C5 \& T5 }\end{array}$ \\
\hline 73.1, F & Nerve & T1-4 & T1-3 & Allograft & SBRT & 2.2 & $\begin{array}{l}\text { Unilateral rod \& screw } \\
\text { breakage at T3 w/ } \\
\text { kyphosis }\end{array}$ & $\begin{array}{l}\text { Extension of instrumentation \& } \\
\text { fusion w/ allograft to C7 \& T6, } \\
\text { replacement of broken T3 screw }\end{array}$ \\
\hline 74.1, F & Bone & T3-4 & T1-7 & Allograft & SBRT & 15.4 & $\begin{array}{l}\text { Loosening of T5 \& T7 } \\
\text { screws }\end{array}$ & $\begin{array}{l}\text { Removal of T5 \& T7 screws, exten- } \\
\text { sion of instrumentation \& fusion } \\
\text { w/ allograft to T10 w/ cement- } \\
\text { augmented screws at T9 \& T10 }\end{array}$ \\
\hline $68.2, \mathrm{M}$ & Renal & L4 & L3-5 & Allograft & SBRT & 18.4 & $\begin{array}{l}\text { Interbody cage subsid- } \\
\text { ence, L3 screw pullout }\end{array}$ & $\begin{array}{l}\text { Replacement of L3 to L5 instrumen- } \\
\text { tation w/ vertebroplasty }\end{array}$ \\
\hline 77.0, M & Renal & C3-5 & C3-5 & Allograft & SBRT & 44.3 & $\begin{array}{l}\text { Anterior C3 screw failure } \\
\text { w/ kyphotic deformity }\end{array}$ & $\begin{array}{l}\text { C3-5 posterior decompression w/ } \\
\text { instrumented fusion C1-T2 }\end{array}$ \\
\hline
\end{tabular}

ing revision among 159 patients undergoing unspecified surgery for metastatic disease. ${ }^{35}$ This unadjusted risk was associated with preoperative radiotherapy; while osteoradionecrosis is a conceivable mechanism, ${ }^{42}$ and while this association has been reported, ${ }^{43}$ it was derived from a model with 7 covariates but only 3 failure events, creating high likelihood of small-sample bias and model inaccuracy.

In a small retrospective study, Longo and colleagues reported a $3.4 \%$ risk of reoperation for hardware failure in 58 patients undergoing instrumented fusion for metastatic disease.$^{37}$ No fusion or survival data were reported. Hardware failure was associated with Eastern Cooperative Oncology Group scores greater than 2 and multiple myeloma histology. These were derived from a multivariate model despite a low number of events, increasing the risk of bias. Furthermore, their reported median time to failure of 6.1 months may be inaccurate; this parameter can be neither estimated without performing survival-type analysis nor directly calculated with less than $50 \%$ of the cohort experiencing failure. Paulino Pereira and colleagues conducted a retrospective study of 647 patients undergoing unspecified surgery for metastatic disease and reported a $1.5 \%$ risk of reoperation for hardware failure..$^{44}$ The proportion of patients in whom hardware was placed or in whom fusion was performed was not presented. Time-to-event analysis was performed for reoperation for any cause but not for hardware failure specifically.

In a study of long-term survivors, Barzilai and colleagues had a high reoperation rate for hardware failure of $12.5 \%$ in 88 patients treated with instrumented fusion (76.1\%) or percutaneous fixation $(23.9 \%)$ and who survived a minimum of 24 months postoperatively. ${ }^{38}$ The risk of failure was $13.4 \%$ in the fusion group and $9.5 \%$ in the percutaneous fixation group, but these rates were not compared with statistical methods. The relatively high rate of hardware failure in this study of long-term survivors suggests that high rates of early death are likely responsible for the predominantly low rates of failure in the literature.

In one study incorporating competing risk-of-death analysis, Amankulor and colleagues reported a reopera- tion rate for hardware failure of $2.8 \%$ in 318 patients who underwent separation surgery for spinal metastasis. ${ }^{36}$ The authors performed multiple univariate analyses for risk factors for hardware failure, reporting associations with constructs greater than 6 levels and chest wall resection. Confidence in these associations is limited by the low event number and especially by the multiplicity of tests performed. A strength of this study is the homogeneity of surgical technique.

We have presented a cumulative incidence of $4.2 \%$ of hardware failure requiring reoperation, adjusted for the competing risk of death. While this is likely consistent with existing studies, comparison is inexact, as most published rates are not risk adjusted. Two cases of early hardware failure (1.1 and 2.2 months postoperatively) are arguably not germane to a discussion of the protective effect of bony arthrodesis, as it is not expected to occur at this time point in any population. One could choose to exclude these cases and produce an even lower "relevant" hardware failure rate. Nevertheless, given the particularly tenuous understanding of the process of arthrodesis in the oncological population and to avoid underestimation of hardware failure, we did not define a minimum time point in our definition of hardware failure. We found a potential relationship between hardware failure and increasing age; increased bone turnover and decreased bone mineral density could theoretically decrease integration of spinal hardware. ${ }^{45,46}$ Our association should be viewed as merely hypothesis generating given the necessity of univariate analysis and the multiple comparisons performed. All 5 patients who experienced hardware failure received allograft, but none achieved complete fusion. Our data do not permit us to make claims regarding the protective effects of partial or complete fusion. The high competing risk of death did appear to result in low rates of both fusion and hardware failure, although further study of primary histologies associated with longer survival is warranted. If postoperative survival continues to increase due to improvements in systemic therapy, hardware failure rates could increase sufficiently to make bony fusion a top priority. Based on 
current data, however, it is reasonable to continue exploring the relative benefits of percutaneous instrumentation and judicious use of allograft products, which may reduce surgical morbidity and healthcare costs.

This is the largest study to incorporate survival, radiographic fusion, and hardware failure data of patients undergoing decompression and instrumented fusion for spinal metastatic disease. Our study has several limitations, including its retrospective, single-center nature and the heterogeneity of the surgical technique. While 81 of 164 patients in the cohort had no imaging follow-up, greater than $80 \%$ of them survived less than the 6 months necessary to have undergone CT scanning in our study, and we have not yet found evidence to justify obtaining a CT scan prior to 6 months to assess fusion. Lastly, as with all studies of this population to date, the low number and rate of hardware failure events limit the ability to perform reliable multivariate risk factor analysis.

\section{Conclusions}

Low rates of complete fusion and hardware failure were observed due to the high competing risk of death. Prospective studies of percutaneous fixation and other nonfusion techniques may be warranted.

\section{References}

1. Lee CS, Jung CH. Metastatic spinal tumor. Asian Spine J. 2012;6(1):71-87.

2. Patchell RA, Tibbs PA, Regine WF, et al. Direct decompressive surgical resection in the treatment of spinal cord compression caused by metastatic cancer: a randomised trial. Lancet. 2005;366(9486):643-648.

3. Vrionis FD, Small J. Surgical management of metastatic spinal neoplasms. Neurosurg Focus. 2003;15(5):E12.

4. Laufer I, Rubin DG, Lis E, et al. The NOMS framework: approach to the treatment of spinal metastatic tumors. Oncologist. 2013;18(6):744-751.

5. Al-Omair A, Masucci L, Masson-Cote L, et al. Surgical resection of epidural disease improves local control following postoperative spine stereotactic body radiotherapy. Neuro Oncol. 2013;15(10):1413-1419.

6. Laufer I, Iorgulescu JB, Chapman T, et al. Local disease control for spinal metastases following "separation surgery" and adjuvant hypofractionated or high-dose single-fraction stereotactic radiosurgery: outcome analysis in 186 patients. $J$ Neurosurg Spine. 2013;18(3):207-214.

7. Kornblum MB, Fischgrund JS, Herkowitz HN, et al. Degenerative lumbar spondylolisthesis with spinal stenosis: a prospective long-term study comparing fusion and pseudarthrosis. Spine (Phila Pa 1976). 2004;29(7):726-734.

8. Chun DS, Baker KC, Hsu WK. Lumbar pseudarthrosis: a review of current diagnosis and treatment. Neurosurg Focus. 2015;39(4):E10.

9. Ekman P, Möller H, Hedlund R. The long-term effect of posterolateral fusion in adult isthmic spondylolisthesis: a randomized controlled study. Spine J. 2005;5(1):36-44.

10. Andersen T, Videbaek TS, Hansen ES, et al. The positive effect of posterolateral lumbar spinal fusion is preserved at long-term follow-up: a RCT with 11-13 year follow-up. Eur Spine J. 2008;17(2):272-280.

11. Kumar N, Patel R, Wadhwa AC, et al. Basic concepts in metal work failure after metastatic spine tumour surgery. Eur Spine J. 2018;27(4):806-814.

12. Panjabi MM. Biomechanical evaluation of spinal fixation devices: I. A conceptual framework. Spine (Phila Pa 1976). 1988;13(10):1129-1134.

13. Elder BD, Ishida W, Goodwin CR, et al. Bone graft options for spinal fusion following resection of spinal column tumors: systematic review and meta-analysis. Neurosurg Focus. 2017;42(1):E16.

14. Ravindra VM, Godzik J, Dailey AT, et al. Vitamin D levels and 1-year fusion outcomes in elective spine surgery: a prospective observational study. Spine (Phila Pa 1976). 2015; 40(19):1536-1541.

15. Yahanda AT, Buchowski JM, Wegner AM. Treatment, complications, and outcomes of metastatic disease of the spine: from Patchell to PROMIS. Ann Transl Med. 2019;7(10):216.

16. Georgiou KR, Scherer MA, Fan CM, et al. Methotrexate chemotherapy reduces osteogenesis but increases adipogenic potential in the bone marrow. J Cell Physiol. 2012;227(3): 909-918.

17. Kim TK, Cho W, Youn SM, Chang UK. The effect of perioperative radiation therapy on spinal bone fusion following spine tumor surgery. J Korean Neurosurg Soc. 2016;59(6):597-603.

18. Ibrahim A, Crockard A, Antonietti P, et al. Does spinal surgery improve the quality of life for those with extradural (spinal) osseous metastases? An international multicenter prospective observational study of 223 patients. Invited submission from the Joint Section Meeting on Disorders of the Spine and Peripheral Nerves, March 2007. J Neurosurg Spine. 2008;8(3):271-278.

19. Czigléczki G, Mezei T, Pollner P, et al. Prognostic factors of surgical complications and overall survival of patients with metastatic spinal tumor. World Neurosurg. 2018;113:e20-e28.

20. Fehlings MG, Nater A, Tetreault L, et al. Survival and clinical outcomes in surgically treated patients with metastatic epidural spinal cord compression: results of the prospective multicenter AOSpine study. J Clin Oncol. 2016;34(3):268-276.

21. Wibmer C, Leithner A, Hofmann G, et al. Survival analysis of 254 patients after manifestation of spinal metastases: evaluation of seven preoperative scoring systems. Spine (Phila Pa 1976). 2011;36(23):1977-1986.

22. Fang T, Dong J, Zhou X, et al. Comparison of mini-open anterior corpectomy and posterior total en bloc spondylectomy for solitary metastases of the thoracolumbar spine. J Neurosurg Spine. 2012;17(4):271-279.

23. Harel R, Chao S, Krishnaney A, et al. Spine instrumentation failure after spine tumor resection and radiation: comparing conventional radiotherapy with stereotactic radiosurgery outcomes. World Neurosurg. 2010;74(4-5):517-522.

24. Chuang HC, Wei ST, Lee HC, et al. Preliminary experience of titanium mesh cages for pathological fracture of middle and lower cervical vertebrae. J Clin Neurosci. 2008;15(11): $1210-1215$.

25. Heidecke V, Rainov NG, Burkert W. Results and outcome of neurosurgical treatment for extradural metastases in the cervical spine. Acta Neurochir (Wien). 2003;145(10):873-881.

26. Oda I, Abumi K, Ito M, et al. Palliative spinal reconstruction using cervical pedicle screws for metastatic lesions of the spine: a retrospective analysis of 32 cases. Spine (Phila $\mathrm{Pa}$ 1976). 2006;31(13):1439-1444.

27. Omeis I, Bekelis K, Gregory A, et al. The use of expandable cages in patients undergoing multilevel corpectomies for metastatic tumors in the cervical spine. Orthopedics. 2010; 33(2):87-92.

28. Dai LY, Jiang LS, Jiang SD. Posterior short-segment fixation with or without fusion for thoracolumbar burst fractures. a five to seven-year prospective randomized study. J Bone Joint Surg Am. 2009;91(5):1033-1041.

29. Ko SB, Lee SW. Result of posterior instrumentation without fusion in the management of thoracolumbar and lumbar unstable burst fracture. J Spinal Disord Tech . 2014;27(4):189-195.

30. Walker CT, Xu DS, Godzik J, et al. Minimally invasive sur- 
gery for thoracolumbar spinal trauma. Ann Transl Med.2018; 6(6):102.

31. Yang H, Shi JH, Ebraheim M, et al. Outcome of thoracolumbar burst fractures treated with indirect reduction and fixation without fusion. Eur Spine J. 2011;20(3):380-386.

32. Bellato RT, Teixeira WG, Torelli AG, et al. Late failure of posterior fixation without bone fusion for vertebral metastases. Acta Ortop Bras. 2015;23(6):303-306.

33. Drakhshandeh D, Miller JA, Fabiano AJ. Instrumented spinal stabilization without fusion for spinal metastatic disease. World Neurosurg. 2018;111:e403-e409.

34. Park SJ, Lee KH, Lee CS, et al. Instrumented surgical treatment for metastatic spinal tumors: is fusion necessary? $J$ Neurosurg Spine. 2019;32(3):456-464.

35. Pedreira R, Abu-Bonsrah N, Karim Ahmed A, et al. Hardware failure in patients with metastatic cancer to the spine. $J$ Clin Neurosci. 2017;45:166-171.

36. Amankulor NM, Xu R, Iorgulescu JB, et al. The incidence and patterns of hardware failure after separation surgery in patients with spinal metastatic tumors. Spine J. 2014;14(9): $1850-1859$.

37. Longo M, De la Garza Ramos R, Gelfand Y, et al. Incidence and predictors of hardware failure after instrumentation for spine metastasis: a single-institutional series. World Neurosurg. 2019;125:e1170-e1175.

38. Barzilai O, McLaughlin L, Lis E, et al. Outcome analysis of surgery for symptomatic spinal metastases in long-term cancer survivors. J Neurosurg Spine. 2019;31(2):285-290.

39. Morgen SS, Lund-Andersen C, Larsen CF, et al. Prognosis in patients with symptomatic metastatic spinal cord compression: survival in different cancer diagnosis in a cohort of 2321 patients. Spine (Phila Pa 1976). 2013;38(16):1362-1367.

40. Dea N, Versteeg A, Fisher C, et al. Adverse events in emergency oncological spine surgery: a prospective analysis. $J$ Neurosurg Spine. 2014;21(5):698-703.

41. Quraishi NA, Rajabian A, Spencer A, et al. Reoperation rates in the surgical treatment of spinal metastases. Spine J. 2015; 15(3)(suppl):S37-S43.

42. Donovan DJ, Huynh TV, Purdom EB, et al. Osteoradionecrosis of the cervical spine resulting from radiotherapy for primary head and neck malignancies: operative and nonoperative management. J Neurosurg Spine. 2005;3(2):159-164.

43. Mesfin A, Sciubba DM, Dea N, et al. Changing the adverse event profile in metastatic spine surgery: an evidence-based approach to target wound complications and instrumentation failure. Spine (Phila Pa 1976). 2016;41(suppl 20):S262-S270.
44. Paulino Pereira NR, Ogink PT, Groot OQ, et al. Complications and reoperations after surgery for 647 patients with spine metastatic disease. Spine J. 2019;19(1):144-156.

45. Garnero P, Hausherr E, Chapuy MC, et al. Markers of bone resorption predict hip fracture in elderly women: the EPIDOS Prospective Study. J Bone Miner Res. 1996;11(10): 1531-1538.

46. Falahati-Nini A, Riggs BL, Atkinson EJ, et al. Relative contributions of testosterone and estrogen in regulating bone resorption and formation in normal elderly men. J Clin Invest. 2000;106(12):1553-1560.

\section{Disclosures}

Dr. Park: consultant for Globus and NuVasive, royalties from Globus, and support of non-study-related clinical or research effort from ISSG and DePuy. Dr. Spratt: consultant for AstraZeneca, Blue Early, and Janssen.

\section{Author Contributions}

Conception and design: Szerlip, Yee, Saadeh, Spratt, Jackson. Acquisition of data: Yee, Saadeh, Strong, Ward, Elswick, Srinivasan. Analysis and interpretation of data: Yee. Drafting the article: Yee. Critically revising the article: Szerlip, Yee, Saadeh, Strong, Ward, Park, Oppenlander. Reviewed submitted version of manuscript: all authors. Approved the final version of the manuscript on behalf of all authors: Szerlip. Statistical analysis: Yee, Strong. Study supervision: Szerlip, Park, Oppenlander.

\section{Supplemental Information}

\section{Previous Presentations}

This project was presented at Spine Summit 2020: AANS/CNS Section on Disorders of the Spine and Peripheral Nerves, Las Vegas, Nevada, March 5-8, 2020.

\section{Correspondence}

Nicholas J. Szerlip: University of Michigan, Ann Arbor, MI. nszerlip@med.umich.edu. 